\title{
CARVER+Shock (Agriculture) - Software for Agriculturists to Fight against Bioterrorism
}

\author{
Vedpal Yadav \\ Lecturer in Food Technology \\ Government Polytechnic, Mandi Adampur \\ Hisar, Haryana, India- 125052
}

\author{
Alka Sharma \\ Chairperson \\ Department of Food Technology, GJU S\&T \\ Hisar, Haryana, India- 125001
}

\begin{abstract}
CARVER+Shock (Agriculture) software is developed by Sandia National Laboratory, USA with the association of USFDA and USDA-APHIS as a food defense tool for farms. In the wake of recent findings on food and agriculture defense studies, it is very useful software to prepare the farm managers to protect against any act and attack of bioterrorism. The software was tested on the north Indian farms and reports are alarming. Authors advise fast and firm actions to be taken to implement the mitigations advised by this hazard analysis process.
\end{abstract}

Keywords- Bio-terrorism; CARVER+Shock; Food Supply Chain Safety; Agroterrorism; Food Safety; Nodes.

\section{INTRODUCTION}

The astonishing specter of September 11, 2001, jarred America and, indeed, all free nations, into accepting the previously unthinkable- the world's only remaining superpower is vulnerable to catastrophic attack and asymmetric warfare, even within its own borders. In a few short hours Americans came to realize that, for a fanatical, resourceful, and patient enemy, there are neither ethical bounds nor societal mores to delineate the nature of the target, the weapon of choice, or the scale of the violence. We know that at least nine countries support offensive terrorism programs, and that Al-Qa'ida- Osama bin Laden's international terrorist organization- has been committed to developing and deploying weapons of mass destruction against any target.

We are now also facing up to a less publicized, but potentially devastating threat-terrorism directed against food and agricultural infrastructure. Farms, food, and agriculture systems are exceedingly vulnerable to deliberate disruption by hostile intent on undermining confidence in food supplies or wreaking havoc on the agricultural sector, which accounts for major part of every country's gross domestic product.

Intelligence reports indicate that a number of countries have active research programs that could produce biological agents to threaten crops and livestock. Naturally occurring outbreaks of diseases signal the devastation that could result from a carefully choreographed intentional release. Thus the recent Foot and mouth disease epidemics in Taiwan and Great Britain, or hog cholera in the Netherlands, or the infection of Florida citrus trees with citrus canker, aptly demonstrate the vulnerability of living targets to biological pathogens and the economic chaos that can result from an outbreak- intentional or otherwise (1).

Agricultural terrorism is specifically addressed in materials captured in U.S.-led Afghanistan campaigns against the alQa'ida terrorist network. This emphasizes that agriculture is a priority target of terrorists. Targeted introduction of a chemical agent harmful to livestock is an area of agricultural terrorism that has not received similar attention as infection with pathogenic zoonotic diseases (For Example Foot-andMouth Disease [FMD], African Swine Fever or Rinderpest) (2).

Experts agree that the single greatest threat to our agricultural economy is foot-and-mouth disease (FMD). An outbreak of this highly-contagious viral disease would have a catastrophic effect, including immediate cessation of beef exports, fullscale quarantines, possible destruction of millions of animals, stop-movement orders, and economic chaos (losses upwards to $\$ 60$ billion). Five primary groups are considered to be threats to agriculture: international terrorists, domestic terrorists, militant animal rights groups, economic opportunists, and disgruntled employees (3).

When U.S. troops entered the caves and safe houses of members of the al-Qa'ida terrorist network in Afghanistan in the months following the September 11th attacks, they found hundreds of pages of U.S. agricultural documents that had been translated into Arabic. A significant part of the group's training manual was reportedly devoted to agricultural terrorism, specifically, the destruction of crops, livestock, and food processing operations (4).

In a recent incident five Muslim soldiers arrested at Fort Jackson for trying to poison the food supply in USA (5).

Such incidents are alarming signs to the new face of terrorism- the bioterrorism. This keyword is not the buzzword for security forces till now but the gap is of just one incident and the whole world will be yelling - bioterrorism, bioterrorism, bioterrorism! (6). While food is an attractive vehicle for a terrorist biological weapon, the use of food as a weapon may be more difficult than initially appears. The events of September 11,2001, and the subsequent anthrax incidents gave rise to concerns about unconventional terrorist attacks, including a similar threat on the U.S. food supply. In the aftermath of those incidents, the Food and Drug Administration (FDA) took steps to improve its ability to prevent, prepare for, and respond to incidents of food contamination. Though motivated by the concerns about deliberate contamination, those activities built upon and expanded the agency's continuing efforts to protect consumers from foods that have been unintentionally contaminated. As part of those activities, FDA assessed the risk to and vulnerability of the U.S. food supply to an act of terrorism. Clearly some foods are not very susceptible to deliberate contamination (7).

CARVER+Shock (Agriculture) is designed to assess the potential for an attacker to successfully contaminate an agricultural food product prior to or during harvest. It is intended for use primarily by farm and ranch operators (8). 


\subsection{Background Information on the CARVER Process \\ 1.1.1. CARVER+Shock}

CARVER+Shock is a software application that can be used to assess vulnerabilities within the food industry. It has been adapted from an offensive targeting prioritization tool used by the U.S. military (CARVER). CARVER+Shock allow the user to think like an attacker to identify the most attractive targets for an attack. A CARVER+Shock assessment of a food production operation, facility, or process can determine vulnerable points in the user's infrastructure, allowing the user to focus resources on protecting the most susceptible points in the system (9)

CARVER is an acronym for the following six attributes :

Criticality: Magnitude of public health and economic impacts of an attack.

Accessibility: Attacker's ability to physically gain access to and leave a target.

Recuperability: Time required to recover from an attack.

Vulnerability: Likelihood that an attack will be successful.

Effect: Direct loss from an attack as measured by loss of production.

Recognizability: Ease of identifying a target.

A seventh attribute, Shock, has been added to the original six to assess the combined health, economic, and psychological impacts of an attack within the food industry. These attributes are used to evaluate the attractiveness of a target for attack (9, 10)

\subsubsection{Application of CARVER+Shock as a Food Defense Tool}

Federal agencies, such as the Food Safety and Inspection Service (FSIS) and the Food and Drug Administration (FDA), have used the CARVER+Shock method to evaluate the potential vulnerabilities of farm-to-table supply chains of various food commodities, as well as individual operations, facilities, and processes. These evaluations are carried out during face-to-face meetings of representatives from a particular segment of the food processing industry and Federal and State food safety agencies, and generally take 2 to 3 days for 20 to 30 s participants $(11,12)$.

Using a scale from one to ten for each of the seven CARVER+Shock attributes, the participants score the target attractiveness of each segment, or "node", on a process diagram of the commodity or facility being evaluated. Conditions that are associated with lower attractiveness (or lower vulnerability) are assigned lower values (1 or 2), whereas conditions associated with higher attractiveness (or higher vulnerability) are assigned higher values ( 9 or 10). The individual scores for each CARVER+Shock attribute are then added together, so that each node in the diagram can have a total score ranging from 7 to $70(8,13)$.

\subsubsection{Need for CARVER+Shock Software}

Conducting face-to-face CARVER+Shock evaluations is resource-intensive and limits the number of evaluations that can reasonably be conducted. Therefore, the FDA and USDA have sponsored development of CARVER+Shock software, which can be downloaded from their web sites, www.fda.gov and www.usda.gov. Having on-line CARVER+Shock software that produces results equivalent to those of a face-to- face session allows members of the food industry to conduct vulnerability assessments of their operations, facilities, or processes on their own (14)

The software tool is expected to be used by State and local food security agencies, industrial providers, farmers and ranchers, food retailers, and any other parties interested in food defense. The tool is designed for use throughout the food processing industry (15).

CARVER+Shock software mimics the face-to-face CARVER+Shock meetings by having the user:

1. Build a diagram for the operation, facility, or process to be evaluated, and

2. Answer a series of questions about the diagram.

Based on the answers given, the software calculates a score for each CARVER+Shock attribute and sums them to produce a total score for each node. As in a face-to-face session, total scores range from one to ten for each CARVER+Shock attribute and from 7 to 70 for each node. The user may view the attribute scores and total for each node, the total scores for all nodes, and the attribute scores for all nodes (For example all the node Criticality scores, Accessibility scores, and so on) (16).

\section{MATERIAL AND METHODS}

CARVER+Shock is a software tool that implements a foodproduction security method used by the Food and Drug Administration's (FDA's) Center for Food Safety and Applied Nutrition (CFSAN). It is intended for use throughout the food industry, from farm to retail. This user's manual is designed to guide the user in applying one module of the software, the CARVER+Shock (Agriculture) module, which is designed primarily for harvest and pre-harvest food-production operations $(17,18)$.

CARVER+Shock refines and optimizes the Criticality, Accessibility, Recognizability, Vulnerability, Effect, Recuperability (CARVER) + Shock security method used by FDA and the United States Department of Agriculture Food Safety and Inspection Service (USDA FSIS). CARVER+Shock has been developed by Sandia National Laboratories for CFSAN, FSIS, and the Institute of Food Technologists (8).

\subsection{Software Description}

CARVER+Shock (Agriculture) is intended for use primarily by farm and ranch operators. It is designed to assess the potential for an attacker to successfully contaminate a food product prior to harvest and its entry into the retail sector for processing or sale to a member of the public $(8,19)$.

This Agriculture module considers four generic categories of contaminating agents that will survive most processes and therefore provide a worst-case scenario:

1. A highly contagious disease that harms the crop or herd,

2. A contagious disease that has the potential to harm humans,

3. A chemical that targets the crop or herd rather than consumers, and

4. A chemical that could cause death or illness in consumers. 
It is estimated that a new software user will take 6 to 8 hours to prepare a process diagram with 15 to 20 steps and answer all the questions.

CARVER+Shock (Agriculture) must run on a screen resolution setting of 1024 by 768 pixels or better. This may or may not require the user to change their personal display options, which may be found with other settings in the control panel (8).

\subsection{Overview of the Software Structure}

The software contains three main sections: diagram, interview, and scoring. Initially, the user will create a chart of the process in the Diagram section. This is followed by the Interview section, which asks specific questions about the diagram. Questions are based on the assumption that a credible attack is one initiated by an "insider," defined as an individual who is on site with company permission (See Figure 1). An insider could be an employee, contractor, vendor, or visitor (such as a member of a public tour). The final section gives results in the form of scores based on the answers provided in the interview section (8).

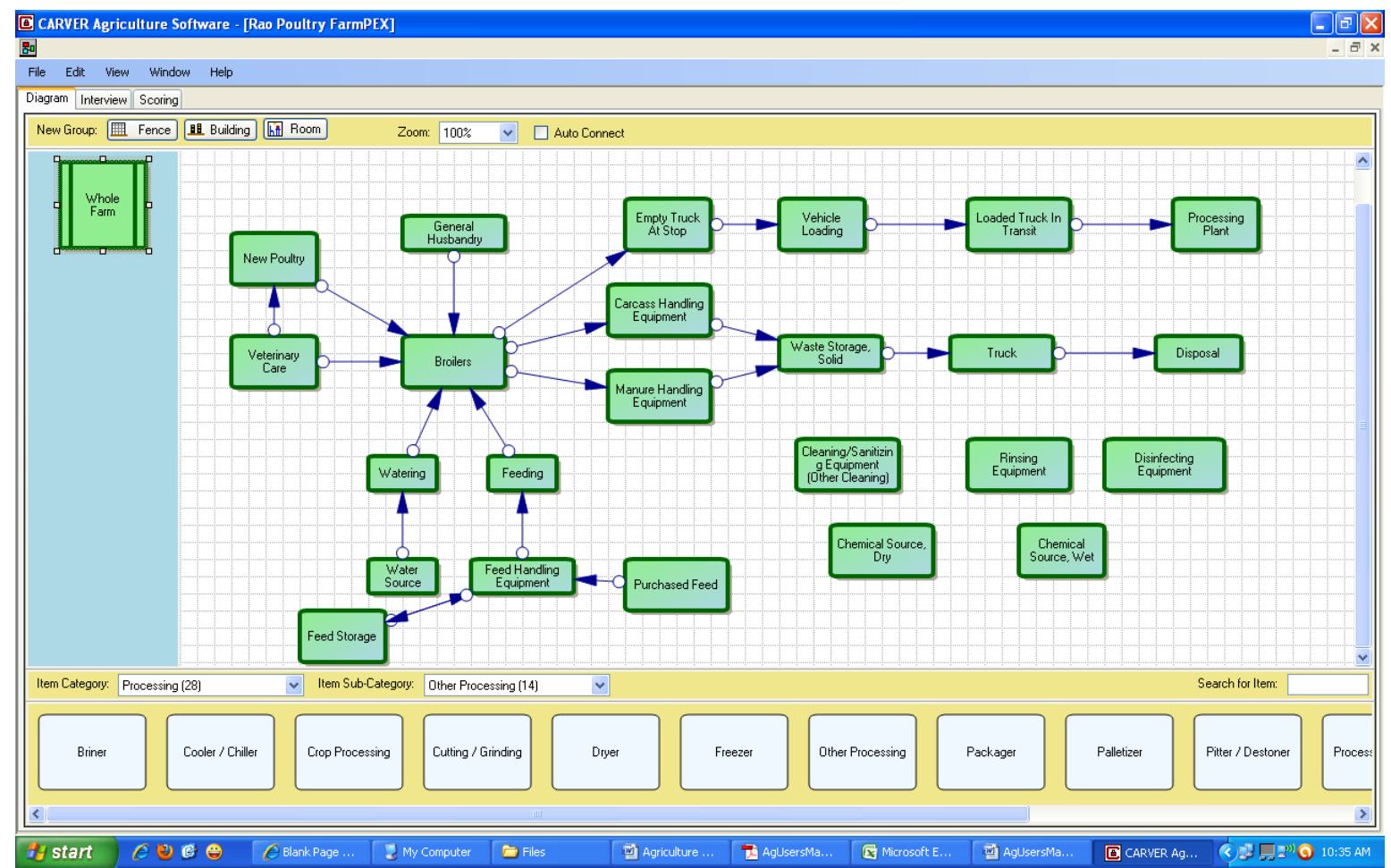

Figure 1 Schematic diagram showing fencing to whole farm

\subsubsection{Diagram Tab}

The process diagram is made up of icons that represent process nodes. A "process node" is a distinct step in the operation being examined. It may be part of the physical plant (e.g., a fence or building) or a processing step (e.g., planting or feeding), but most of the process nodes considered by CARVER+Shock are equipment. Process nodes are represented by "icons," small graphical elements used to build the process diagram (8).
On the Diagram tab, various categories of process nodes can be chosen from a dropdown list. Icons for the selected category become available to add to the diagram (See Figure 2).

The diagram of the operation may also be created and displayed in the form of a list that can be used with a screen reader. To use this option, select List View under the View menu. 


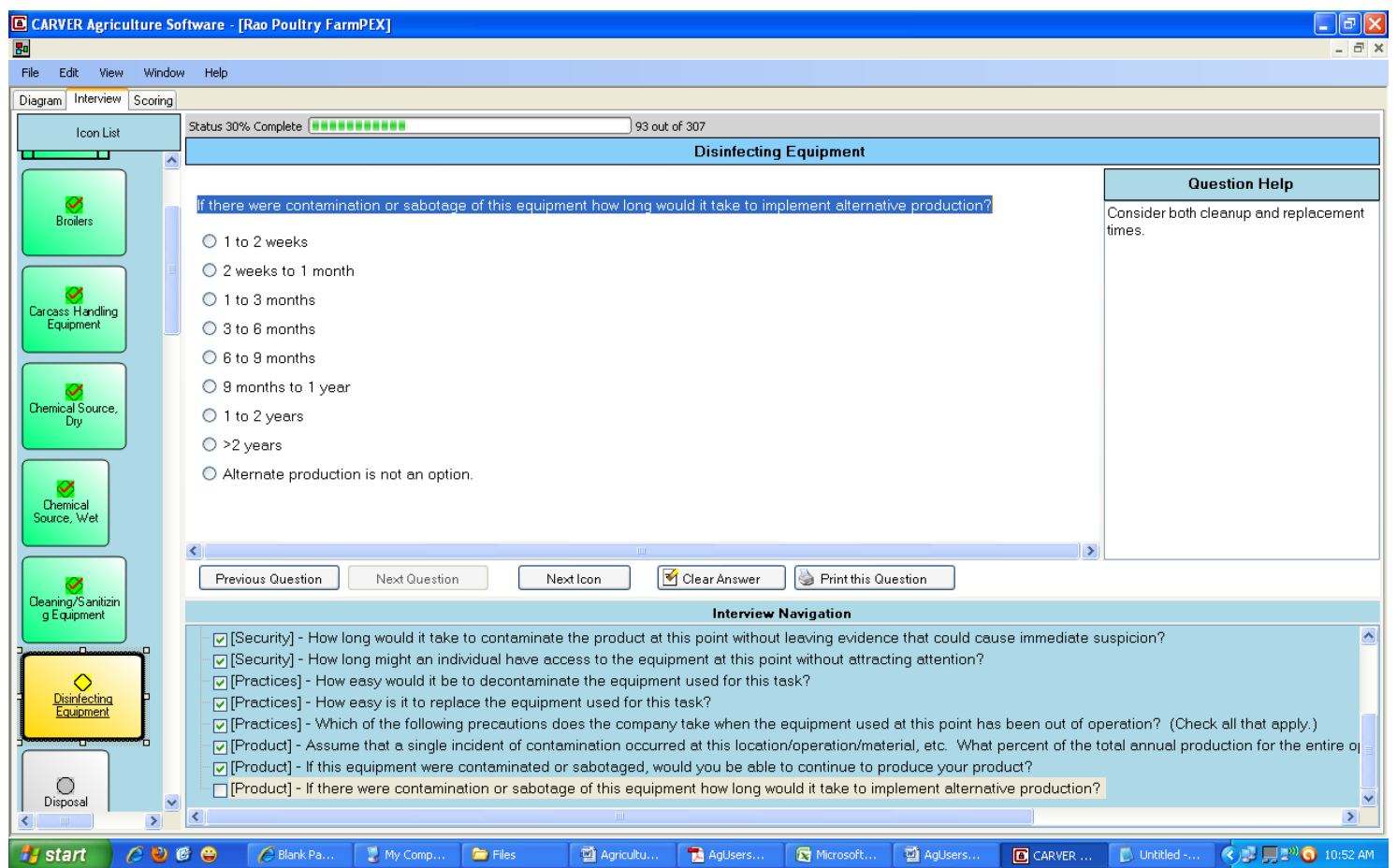

Figure 2 Interview tab showing questions

\subsubsection{Interview Tab}

The Interview tab asks specific questions for each icon in the diagram of the operation. Questions that have been answered are checked in the lower panel of the screen, and unchecked questions have not been answered. Each icon used to create the process diagram is shown on a vertical bar on the left side of the screen, called the "vertical icon bar," and color-coded. A white icon with an empty circle above its name has no answered questions. A yellow icon with an empty diamond means that some, but not all, of its questions have been answered (See Figure 3). A green icon with a check mark in the diamond means all questions have been answered for that icon. The questions address a number of factors that are considered in the CARVER+Shock scoring (8).

Not all the topics will be addressed for all process nodes. After the questions for all process nodes have been answered, the results become available on the Scoring tab.

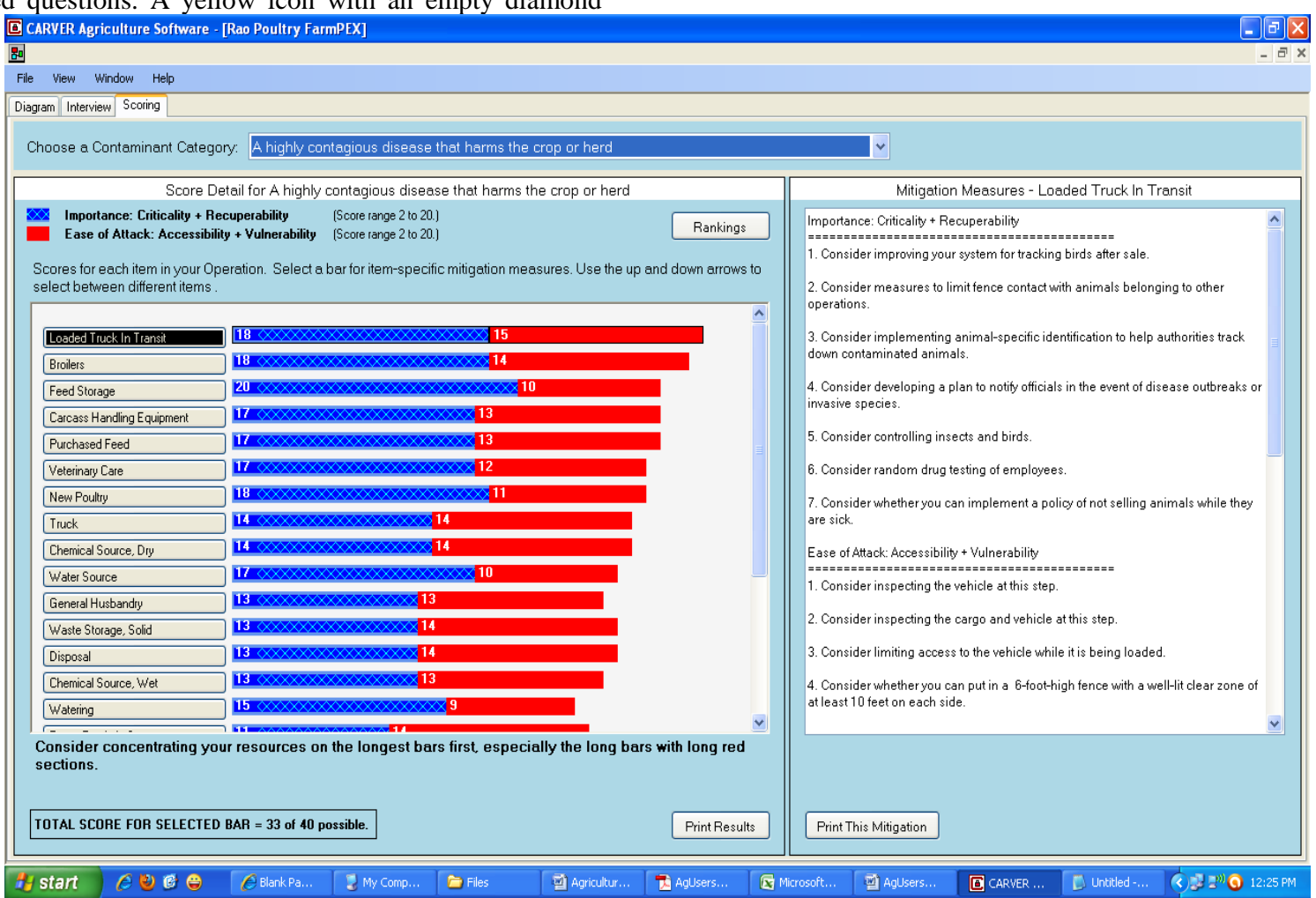

Figure 3 Scoring tab showing the results and suggestions 


\subsubsection{Scoring Tab}

After all questions are answered, the Scoring tab will present scores for each process step and initial actions that you might take in improving security for that process step.

The overall results for each process step are available in a bar graph. The bar graph shows the results both numerically and as shorter and longer bars.

Double-clicking on a specific bar displays the process node's individual assessment. This provides more detailed information regarding the individual process node, including individual scores for each aspect of CARVER+Shock, total score, and maximum possible score. On the bar-graph screen, selecting any bar will bring up mitigation text for that aspect of CARVER+Shock, with suggestions for improving processnode security (8).

List of all diagram process node icons that are currently available in the CARVER+Shock (Agriculture) software, organized by categories.

\section{RESULTS AND DISCUSSIONS}

The software version 2.0.2.0 has no significant changes in structure from its earlier avatar, version 1.0.0.0. The evident changes are availability of agriculture specific case studies and questionnaire. This is also evident from the name too CARVER+Shock (Agriculture)

- The links provided in help menu are hyperlinked to USFDA's Food Defense \& Emergency Response and USDA-APHIS-Emergency Preparedness and Response. The detailed support pages are very informative of the food defense program in US. This is welcomed as it opens whole new world of food defense program in US.

- In the Help menu there must be an auto update link to update the patches, if any.

- Apart from these preliminary findings there are some industry specific requirements which can be met by the meetings of the programmers and the industry people from time to time.

- To report the bugs there is a form at the end of the manual. This is a good attitude but for software issues bug reporting must be done online. A link for bug reporting and online help is must to make this software a great success. Like its earlier version, this feature is thought to be left consciously otherwise it's a must for software like this.

- Taking into consideration of attention span of a normal human being 12 to 14 hours of assessment are too long to do. For that a pre assessment version or step must be incorporated. This would give outline of the whole software and rough estimate of the premises in question resulting in greater acceptability of this software which is the ultimate intended goal of developing this software. In many cases the whole report filling and result generation took 4-5 sittings of 2-3 hours each with the key persons in the farm operations, thus resulting in low turnout of case studies and longer than expected time of researching.

- Repetitive questions for similar machines established in the farm caused boredom and disinterest to the resource person and hence disinterest in the question answer session. This issue can be resolved by making questionnaire appealing with audio visual aids.
- In some cases farmers were benefitted by identifying loopholes in the process and with a healthy discussion came out with innovative ideas for food process safety as well as improved and efficient management of resources.

\section{CONCLUSION}

Most of the work related to this product testing was done on the farms of north India, thus the results have the regional, social and cultural biases. After conducting hazard analysis with the help of this software, the gravity of the sorry state of affairs in food safety and food supply chain defense was found to be alarming. The main thing curtaining the farming from bioterrorism is social networking and peer penetration to the vicinity for foreign personnel activity rather than the management of food safety issues. The other factor in favor of food defense came out to be low turnover projects thereby more personal attention of the personnel employed and lower impact on society due to low volume of infection making it less attractive for terrorist groups. Though these are all untested hypothetical factors in favor of food defense in agriculture sector otherwise the condition of this sector is quite welcoming for terrorists for any such attack in the absence of any safety measure or initiative from the farm management. Now the government must initiate the steps in form of some incentive or subsidy to the farms opting for CARVER or any other food defense program for hazard analysis against bioterrorism on their farms. Projects and research in this area can lead to better equipped agriculture sector against agricultural terrorism.

\section{REFERENCES}

[1] Parker, H.S. 2002. Agricultural Bioterrorism: A Federal Strategy to Meet the Threat. In McNair Paper 65. Washington, D.C.: Institute for National Strategic Studies.

[2] Kosal, M.E., and Anderson, D.E. 2004. An unaddressed issue of agricultural terrorism: A case study on feed security. Journal of Animal Science. 82:3394-3400.

[3] Knowles, T.L., Lane, J., Bayens, G., Speer, N.C., Jaax, J., Carter, D.L., and Bannister, A.J. 2005. Defining Law Enforcement's Role in Protecting American Agriculture from Agroterrorism. In NIJ Research Report. S.L. Woerle, editor. Washington, D.C.: National Institute of Justice.

[4] Hui, Y.H. 2006. Handbook of Food Science, Technology, and Engineering: CRC Press, Taylor \& Francis Group.

[5] Robert. 2010. Five Muslim soldiers arrested at Fort Jackson for trying to poison the food supply. http://www.jihadwatch.org.

[6] Busta, F.F. 2007. Recent Developments in the National Center for Food Protection and Defense. In Global Food Safety \& Quality Conference. C.M. Bryant, editor. Minnesota, USA: University of Minnesota, USA.

[7] Armstrong David, J. 2006. Food as a Weapon of Terrorism. In Advances in Microbial Food Safety. Washington, DC: American Chemical Society. 311-325.

[8] Pohl, P. 2009. CARVER + Shock (Agriculture) User's Manual. US FDA, Sandia National Laboratories, IFT.

[9] Acheson, D.W.K. 2007. CARVER + Shock -Introduction and Food Regulatory Agency Goals. In Global Food Safety \& Quality Conference. C.M. Bryant, editor. Minnesota, USA: University of Minnesota, USA. 
[10] Barringer, A.A. 2007. Staying ALERT about Food Defense.

[11] Brackett, R.E. 2005. Subcommittee on the Federal Workforce and Agency Organization Committee on Government Reform.

[12] FDA. 2007. CARVER+Shock. Sandia National Laboratory.

[13] Catlin, M., and Kautter, D. 2007. An Overview of the Carver Plus Shock Method for Food Sector Vulnerability Assessments. USFDA, editor: USFDA. 1-14.

[14] USFDA. 2007. How You Can Enhance Food Security.
[15] Wordpress. 2007. Guard Against Agroterrorism.

[16] USFDA. 2008. CARVER + Shock: Enhancing Food Defense. USFDA.

[17] USFDA. 2007. What is CARVER + Shock?

[18] SPPA. 2006. Threat Assessments and Strategic Partnership Program Agroterrorism (SPPA).

[19] SPAA. 2007. Strategic Partnership Program Agroterrorism (SPPA) Initiative. 